\title{
Justiça social e discurso neoliberal: \\ problematizações sobre a base nacional comum curricular ${ }^{1}$
}

\author{
Social justice and neoliberal discourse: \\ problematizations about national curriculum common core \\ Justicia socialy discurso neoliberal:
problematizaciones sobre la base nacional curricular común
}

Simone Gonçalves da Silva*
Juliana Mezomo Cantarelli*

Resumo

Neste estudo, objetiva-se analisar, a partir da Base Nacional Comum Curricular (BNCC), os atravessamentos do discurso neoliberal na escola em prol da justiça social. Para tanto, a pesquisa, de abordagem qualitativa e de cunho bibliográfico, parte do entendimento de que, por meio da justiça curricular, a escola contempla todos os aspectos da formação dos estudantes, podendo contribuir efetivamente para a justiça social. Porém, durante a análise da política BNCC, percebeu-se que a proposta está alinhada a um projeto neoliberal que atende ao capital e à iniciativa privada. Para a lógica neoliberal, é a economia que rege os assuntos governamentais e transforma os indivíduos em consumidores, inclusive do ensino. Desse modo, para que a escola possa se tornar um espaço de justiça social, é necessário, dentre outros aspectos, assumir-se como um espaço de lutas e tensões na constituição de um projeto de educação antagônico ao vigente, ou seja, um projeto que vise à democracia, à solidariedade e ao bem comum.

Palavras-chave: BNCC. Discurso neoliberal. Justiça curricular. Justiça social. Política educacional.

\section{Abstract}

This study aims to analyze the National Curriculum Common Core (BNCC) of the neoliberal discourse in the school in favor of social justice. For this, the research of a qualitative and bibliographical approach starts from the understanding that through curricular justice (TORRES SANTOMÉ, 2013) the school covers all aspects of student education and can contribute effectively to social justice (FRASER, 2012). However, during the analysis of the BNCC policy, it was perceived that the proposal is aligned with a neoliberal project that serves capital and private initiative. For the neoliberal logic is the economy that government proposition and converts individuals

\author{
Recebido em 31/03/2019 - Aprovado em 03/07/2019 \\ http://dx.doi.org/10.5335/rep.v26i3.9267
}

Doutora em Educação pela Universidade Federal de Pelotas (UFPel), pós-doutoranda na mesma instituição. É pesquisadora no Grupo de Pesquisa em Gestão, Currículo e Políticas Educativas vinculado ao Centro de Estudos em Políticas Educativas: Gestão, Currículo e Trabalho Docente da Faculdade de Educação da UFPel. Brasil. ORCID: 00000001-5159-2454. E-mail: silva.simonegon@gmail.com

** Mestre em Educação pela Universidade Federal de Santa Maria (UFSM). É docente efetiva do Instituto Federal Farroupilha, lotada no campus Júlio de Castilhos. Brasil. ORCID: 0000-0003-3007-7810. E-mail: jucacantarelli@yahoo.com.br 
into consumers, including education. Thus, in order for the school to become an emplacement of social justice, it is necessary, among other things, to assume a emplacement of struggles and tensions in the constitution of an education project antagonistic to that in force, that is, a project aimed at democracy, solidarity and the common good.

Keywords: BNCC. Neoliberal discourse. Curricular justice. Social justice. Educational policies.

\title{
Resumen
}

\begin{abstract}
En este estudio objetivase analizar partiendo de la Base Nacional Común Curricular- BNCC los cruzamientos del discurso neoliberal en la escuela a favor de la justicia social. Por lo tanto, la investigación de enfoque cualitativa y de cuño bibliográfica sale del entendimiento que por medio de la justicia curricular (TORRES SANTOME, 2013) la escuela cubre todos los aspectos de la formación de los estudiantes, pudiendo contribuir efectivamente para la justicia social (NANCY FRASER, 2012). Sin embargo, durante el análisis de la política de BNCC, se percibió que la propuesta está alineada con un proyecto neoliberal que atiende a iniciativas de capital privadas. Para la lógica neoliberal es la economía que gobierna los asuntos gubernamentales y convierte a los individuos en consumidores, incluso la educación. De este modo, para que la escuela pueda convertirse en un espacio de justicia social se requiere entre otras, asumirse como un espacio de lucha y s tensiones en la constitución de un proyecto de educación antagonista al actual, es decir, un proyecto que tiene como objetivo democracia, solidaridad y el bien común.
\end{abstract}

Palabras clave: BNCC. Discurso neoliberal. Justicia curricular. Justicia social. Política educativa.

\section{Introdução}

O presente estudo tem como objetivo analisar, a partir da Base Nacional Comum Curricular (BNCC), os atravessamentos do discurso neoliberal na escola em prol da justiça social. Para tanto, a pesquisa, de abordagem qualitativa e de cunho bibliográfico, parte do pressuposto de que o sistema educacional de massa foi criado pelo Estado, na Europa, em meados do século XIX, com o intuito de intervir na vida da classe trabalhadora. Com isso, a escola se transforma em um espaço de esperança para as crianças oriundas de famílias pobres que sofrerão os efeitos positivos e negativos das ações nela desenvolvidas (CONNEL, 2013).

Nessa perspectiva, a escola deve ter como objetivo contribuir para a justiça social, a partir da justiça curricular, contemplando assim todos os aspectos da formação dos alunos. No entanto, percebe-se a influência das políticas educacionais neoliberais, dentre elas a proposta de uma orientação do currículo em âmbito nacional, iniciado em 2015, intitulada como Base Nacional Comum Curricular. Lançada pelo Ministério da Educação, visa definir

[...] o conjunto orgânico e progressivo de aprendizagens essenciais que todos os alunos devem desenvolver ao longo das etapas e modalidades da Educação Básica, de modo a que tenham assegurados seus direitos de aprendizagem e desenvolvimento (BRASIL, 2018, p. 9, grifo do documento). 
Entretanto, a proposta da base é um tema muito polêmico. Para os defensores, a proposta significa a possibilidade de democratizar o conhecimento, permitindo uma equalização das desigualdades educacionais pela promoção da qualidade da educação. Enquanto que, para os contrários, a proposta representa um silenciamento das vozes dos grupos subalternos e uma padronização que tem por objetivo a concentração das ações na lógica das parcerias público-privadas, com um forte controle sobre o currículo e o trabalho dos professores a partir da avaliação, dos exames padronizados e dos índices métricos.

Assim, percebe-se que, no cenário contemporâneo, sob a hegemonia da orientação neoliberal, muitas políticas educacionais acabam reduzindo a autonomia dos professores e, consequentemente, da escola, bem como das práticas pedagógicas e curriculares. Somam-se a isso as ações que colocam na meritocracia a justificativa para o sucesso e o fracasso individual, responsabilizando somente o estudante pelos seus resultados. Portanto, para a lógica neoliberal, é a economia que rege os assuntos governamentais e transforma os indivíduos em consumidores, inclusive do próprio ensino.

Para que a escola possa se tornar um espaço de justiça social, é necessário, dentre outros aspectos, assumir-se como um espaço de lutas e tensões. É com base nessa última afirmativa que se pretende aprofundar esta discussão, ao problematizar: como a BNCC se constitui em um discurso neoliberal que postula desafios à noção de justiça social na educação?

Para tal, a discussão foi organizada em duas seções: a primeira situa brevemente as reformas e políticas educacionais e curriculares no cenário brasileiro, como o processo de implementação da BNCC, que apresentam como pauta a produção de um currículo neoliberal (BALL, 2010). Na segunda seção, empreende-se um exercício crítico sobre a discussão de justiça curricular de Torres Santomé (2013), que estabelece algumas aproximações com a noção de justiça social de Nancy Fraser (2012), visando compreender os sentidos em disputa na constituição das políticas educacionais curriculares, especificamente a BNCC. Nas considerações finais, são retomados os aspectos tidos como fundamentais, sobretudo no que se referem aos possíveis desafios que a proposição de uma base nacional comum curricular ocupa no cenário educacional contemporâneo a partir da noção de justiça social, em sua potencialidade conceitual. 


\section{Reformas políticas educacionais e curriculares: contextualizando a BNCC}

As políticas educacionais brasileiras desencadeadas nos anos finais da década de 1980 e no início da década de 1990 estão inseridas no contexto das reformas baseadas em prerrogativas neoliberais. A consolidação e a implementação dessas políticas são esforços empreendidos pela introdução de um conjunto de estratégias a fim de supostamente solucionar os problemas da qualidade do ensino e da aprendizagem na educação pública.

A reforma educacional aparece fortalecida com o discurso da importância da educação para o desenvolvimento global e também na esfera nacional. A proliferação desses discursos interessados nos problemas educacionais emerge das redes internacionais de influência que estão cada vez mais preocupadas com um acordo global. Os Estados nacionais passam a discutir a construção de políticas educativas que, de fato, constituem-se em uma combinação de ideias muito próximas. As reformas administrativas e seus discursos passam a instituir uma educação escolarizada como necessidade de mudança, que passa a justificar o empreendimento das políticas educacionais. Os investimentos em educação devem alcançar uma determinada meta de qualidade padronizada, que são obtidas com os modelos convergentes.

O discurso da necessidade da reforma educacional está relacionado como “[...] parte inevitável da globalização e do mercado internacional e de uma economia cada vez mais baseada no conhecimento e que, portanto, exige mudanças radicais na forma de organizar, conceber e desenvolver a educação" (HYPOLITO, 2010, p. 1340). Assim, a educação vem sendo constituída no conjunto das políticas por ações nacionais e internacionais que pretendem averiguar a atuação e o nível de conhecimento desenvolvido nas escolas.

Com isso, as políticas educacionais surgem de um pacote de reformas elaborado pela Organização para Cooperação e Desenvolvimento Econômico (OCDE) ${ }^{2}$. Desde os anos de 1960, a OCDE desempenha um papel importante no cenário mundial. É um órgão internacional, criado na França, para complementar a gestão do Plano Marshall para a reconstrução da Europa após a Segunda Guerra Mundial, com o objetivo de contribuir para o desenvolvimento econômico por meio de assessoria aos governos sobre a administração das políticas públicas. Para ser membro da OCDE, cada nação precisa se comprometer com a economia de mercado, a democracia liberal e os direitos humanos, e dentre suas metas as principais são: aumentar o desenvolvimento econômico e contribuir com o comércio interna- 
cional. Atualmente a organização conta com a participação de 34 países (BALL, 2001; CARVALHO, 2016; LINGARD, 2016).

A partir dos anos de 1990, a OCDE começa a ter um enfoque maior no campo educacional, preocupando-se com resultados estandardizados e comparativos internacionais entre os países, modificando seus objetivos, que anteriormente estavam voltados aos resultados individuais de cada país. Com o movimento dos membros da OCDE para o desenvolvimento de uma estatística educacional comparativa internacional, foi elaborado o relatório Education at a glance. Esse incluiu o compêndio de dados dos países membros e a criação de indicadores, forjando assim o contexto propício à criação do Programa para Avaliação Internacional de Estudantes (Pisa). Segundo destacam Newman e Clarke (2012, p. 368), o Pisa serve para "[...] avaliar e comparar desfechos educacionais entre nações participantes e tem orientado intercâmbios de políticas, ansiedade comparativa e posicionamento competitivo".

Desse modo, o Pisa, organizado pela OCDE, torna central a discussão da educação e a captura da participação dos países nos testes que ocorrem em virtude de uma dinâmica concorrencial que no ano 2000 teve pela primeira vez sua administração (CARVALHO, 2016; LINGARD, 2016). Percebe-se que o trabalho da OCDE não foi sempre da mesma maneira e a sua reconfiguração, no final dos anos de 1990, está inserida no contexto de uma racionalidade neoliberal, numa sociedade pautada pelos mecanismos de concorrência, fazendo com que a educação adquira um papel mais central nesse cenário.

As políticas educacionais como foco de orientações internacionais, como o caso do pacote de reformas orientado pela OCDE, tornam-se possíveis pela mobilização de um "[...] conjunto de experts, centros estatísticos, bancos de dados, seminários mundiais e regionais, documentos, programas de metas regionais, revistas etc." (GARCIA, 2010, p. 449), que também apresentam considerações importantes sobre a educação brasileira, em caso específico. Cabe observar, como coloca Garcia (2010), ao fazer referência a Bauman, que se vive em um mundo "glocalizado", com processos diferenciados entre o contexto global e o contexto local. Contextos esses permeados por discursos da globalização e das políticas neoliberais desenvolvidas especialmente pelos organismos internacionais, como o Banco Mundial (BM), o Fundo Monetário Internacional (FMI), a Organização das Nações Unidas para a Educação, a Ciência e a Cultura (UNESCO) e a OCDE. Esses discursos nem sempre tendem a convergir, mas possuem em comum “[...] a promessa de inclusão, progresso e desenvolvimento, riqueza, democracia, igualdade e qualidade de vida para todos que se inserirem no mercado e na cultura globais" (GARCIA, 2010, p. 447). 
Nesse cenário, é preciso compreender a influência das pesquisas educacionais internacionais sobre a educação brasileira. Para Ball (2011), nesse contexto são alteradas as relações entre a pesquisa educacional e as políticas, determinadas por colocações de expertises em políticas educacionais que passam a orientar as reformas educacionais. Conforme Popkewitz (2004), a reforma configura-se como uma estratégia de administração da liberdade, passando a representar a organização de sistemas de conhecimentos de profissionais e especialistas. Alguns pesquisadores passam a estabelecer novas relações com a política, passando a "[...] assumir novas identidades, como 'pesquisadores da eficácia escolar' e 'teóricos do gerenciamento"' (BALL, 2011, p. 82). As pesquisas desenvolvidas nessa direção privilegiam temáticas relacionadas ao projeto político e ao discurso da política e da reforma educacional neoliberal, como: qualidade, liderança, responsabilização e avaliação (BALL, 2011). Nessa direção, identificam-se as inúmeras políticas educacionais brasileiras desencadeadas como indutoras da qualidade na educação e como instauradoras de novas significações nos processos educativos, entre elas a BNCC.

A defesa da padronização e unificação dos processos de ensino e aprendizagem nas escolas brasileiras, desde a educação infantil até o ensino médio, não é recente no país. Isso envolve uma relação de conservação e continuidade de propostas curriculares anteriores. Por exemplo, a condução das metas e diretrizes presentes nas políticas educacionais brasileiras está relacionada a compromissos assumidos em atividades internacionais, especialmente a Conferência Mundial de Educação para Todos, organizada pela UNESCO em março de 1990 e realizada em Jomtien, na Tailândia. Posteriormente, a UNESCO encomenda o relatório "Educação: um tesouro a descobrir", elaborado em 1996, pela Comissão Internacional sobre Educação para o século XXI. Esse relatório, conhecido internacionalmente como Relatório Delors, delineia orientações relativas à educação básica e às necessidades educativas fundamentais no contexto mundial, aprofundando as reflexões desenvolvidas na Conferência de Jomtien. O relatório tem como objetivo apresentar quatro pilares da educação para o desenvolvimento educacional ao longo da vida no novo milênio: i) aprender a conhecer/aprender a aprender; ii) aprender a fazer; iii) aprender a conviver; iv) aprender a ser (DELORS, 1996).

O documento apresentado da BNCC mostra que a proposta está amplamente ancorada por legislações formuladas que garantam os princípios democráticos desde o final dos anos 1980, conforme justificativa apresentada na sua parte introdutória - seção marcos legais. A BNCC é um documento normativo que teve sua elaboração iniciada em 2015, mas que aparece previsto desde a Constituição 
de 1988. Posteriormente à Constituição, aparecem também a Lei de Diretrizes e Bases da Educação Nacional - Lei no 9.394/1996, as Diretrizes Curriculares Nacionais, os Parâmetros Curriculares Nacionais (1997), para estruturação do Sistema Nacional de Educação, e a aprovação do Plano Nacional de Educação (2014-2024) - Lei n⿳0 13.005/2014. A partir disso, a BNCC justifica sua elaboração por estar articulada às demais políticas educacionais e, portanto, objetiva elevar a qualidade do ensino em todo o Brasil, ao indicar a aprendizagem esperada na educação básica, contribuindo para a melhoria da educação evidenciada pelo baixo desempenho dos estudantes nas avaliações externas nacionais e internacionais (BRASIL, 2018).

A BNCC foi lançada pelo Ministério da Educação, que iniciou sua elaboração em 2015, sendo produzidas três versões de sua redação. O texto final do documento referente à educação infantil e ao ensino fundamental foi homologado no dia 20 de dezembro de 2017, pelo Presidente da República, Michel Temer, e pelo Ministro da Educação, Mendonça Filho. A parte do documento referente ao ensino médio foi entregue posteriormente, em abril de 2018, para avaliação no Conselho Nacional de Educação (CNE), em virtude da discussão da Reforma do Ensino Médio, teve a sua aprovação e homologação em 14 de dezembro de 2018.

Com base nessa proposta de construção de um currículo unificado das aprendizagens, os sistemas de ensino, os professores e os gestores de todo o país estão sendo convocados a se mobilizar em torno do documento BNCC, que, conforme consta, visa orientar a revisão e a elaboração dos currículos dos sistemas e das redes de ensino de todas as escolas públicas e privadas de educação infantil, ensino fundamental e ensino médio, em âmbito nacional. Isso, conforme o documento, como forma de assegurar a garantia dos direitos à aprendizagem, de contribuir com a formação dos professores, de orientar a elaboração dos recursos didáticos e pedagógicos e de melhorar os resultados nas avaliações externas. $\mathrm{O}$ documento ainda defende que a base comum tem como finalidade assegurar as orientações dos princípios para uma formação integral, em uma sociedade democrática, justa e inclusiva.

A BNCC gira em torno da busca de um sentido e significado de qualidade da educação, que envolve setores do governo e da sociedade civil, por meio de instituições e fundações. Tem-se como exemplo a afirmativa de que a proposta do documento não está conduzida somente pela orientação dos marcos legais, mas que ganha força com o Movimento pela Base Nacional Comum, iniciado e constituído em 2013, a partir do "Seminário Internacional Liderando Reformas Educacionais, ocorrido nos EUA, organizado e patrocinado pela Fundação Lemann” (MACEDO, 
2014, p. 1540). O grupo não governamental vem sendo formado por pessoas e instituições que atuam na área de educação, entre as quais: Associação Brasileira de Avaliação Educacional (Abave); Cenpec Educação e Cultura; Comunidade Educativa (Cedac); Consed; Fundação Lemann; Instituto Inspirare; Instituto Ayrton Senna; Instituto Natura; Instituto Unibanco; Todos pela Educação; Undime; entre outros ${ }^{3}$.

O grupo composto por instituições e profissionais ligados à educação tem como pauta a criação de uma base nacional comum, promovendo e apoiando debates, pesquisas e estudos e mobilizando outros atores sobre o assunto da qualidade educacional brasileira, preocupados com a investigação e apreciação das "boas práticas" aos casos de excelência e sucesso de outros países que possuem um currículo unificado. Para o grupo, a criação deste documento

[...] era um passo crucial para promover a equidade educacional e o alinhamento de elementos do sistema brasileiro: a criação de uma Base serviria como "espinha dorsal" para os direitos de aprendizagem de cada aluno, a formação dos professores, os recursos didáticos e as avaliações externas (MOVIMENTO PELA BASE NACIONAL COMUM, 2013, não paginado).

Percebe-se que o discurso da necessidade da reforma educacional está relacionado a uma estrutura organizacional de redes para a indução das políticas educacionais, como proposta "[...] de políticas regional e global e cada vez mais um assunto de comércio internacional. A educação é, em vários sentidos, uma oportunidade de negócios" (BALL, 2004, p. 1108). As reformas educacionais brasileiras têm privilegiado o desempenho orientado pelos resultados das políticas avaliativas, como é o caso da discussão do Movimento pela Base Nacional Comum, que defende a criação do documento como uma necessidade para melhorar o desempenho dos estudantes nas avaliações externas e, consequentemente, a qualidade da educação.

As mudanças empreendidas na educação brasileira nos últimos anos, com a construção e elaboração das principais políticas, programas e projetos educacionais, são investimentos com a promessa de qualificar o sistema público educacional. Essa série de iniciativas emerge em sua maioria de agendas internacionais que potencializam a meritocracia, a eficiência, a competitividade, a comparação e o resultado. A denominada qualidade sustenta a ideia da participação da sociedade como um todo rumo à construção de uma educação pública de qualidade, com elevação dos resultados métricos, para um país em desenvolvimento.

Como exemplo, já citado anteriormente, tem-se o Movimento pela Base Nacional Comum, que envolve vários setores da sociedade em prol de uma suposta 
educação básica de qualidade para todas as crianças e os jovens brasileiros. Além disso, posiciona-se como uma ferramenta em defesa da garantia dos direitos de aprendizagem e de mobilização na elevação da escolarização e tem se sustentado na importância do voluntariado, da solidariedade e da responsabilidade social; entretanto, visa de fato o vasto mercado educacional e a imposição de uma agenda neoliberal.

A discussão da BNCC requer várias considerações, sobretudo o questionamento de que projeto de sociedade e de formação e qual agenda educacional pretendida estão em curso no processo de defesa de uma BNCC. Percebe-se a inserção da produção de um currículo neoliberal (BALL, 2010), que se sustenta em três esferas: currículo neoliberal da reforma do setor público - lógica gerencialista no modo de administração pública; neoliberalismo "no" currículo, com a produção do modo de ser estudante como empreendedor capaz de gerenciar sua própria vida; e o currículo como uma oportunidade de lucro, como a oferta de produtos e serviços educacionais, como materiais didáticos, consultorias e atividades de formação. Portanto, parece que no cenário brasileiro está em andamento um projeto de sociedade neoliberal que sustenta uma pauta educacional em defesa da BNCC, como um currículo neoliberal que implica desafios a um projeto educacional em prol da justiça social.

\section{BNCC e justiça social}

A escola compreendida enquanto instituição social não deve apenas reproduzir as ideias dominantes, ela deve atrelar o ensino às realidades sociais, para não perder seu sentido de continuidade, mas também de ruptura dessa mesma sociedade, por vezes tão desigual. Nessa mesma linha, Charlot (2013) argumenta que a escola tem o papel de difundir o conhecimento científico, mas também tem uma função cultural e social, além da preparação do estudante para ocupar um lugar na divisão social do trabalho. Sendo assim, a escola e sua proposta pedagógica devem considerar a justiça social no seu cotidiano e na formação de seus alunos, refletindo e questionando o modelo neoliberal, que transforma a educação e tudo que a ela se relaciona numa simples oportunidade de lucro.

Destaca-se que, nessa discussão, compreende-se por justiça social o conceito criado por Nancy Fraser (2012), que engloba a redistribuição, o reconhecimento e a paridade de participação. 
O que é preciso é um único princípio normativo que inclua as reivindicações justificadas quer de redistribuição, quer de reconhecimento, sem reduzir umas às outras. Com este propósito, proponho o princípio de paridade de participação, segundo o qual a justiça requer arranjos sociais que permitam a todos os membros (adultos) da sociedade interagir entre si como pares (FRASER, 2002, p. 13).

Assim, segundo a autora, para se combater a injustiça econômica, da qual faz parte a exploração do trabalho, a privação a um padrão material de vida adequado à dignidade, além de ser obrigado a realizar um trabalho indesejado e mal pago, é necessária a redistribuição, ou seja, alguma espécie de reestruturação político-econômica. Já, para se combater a injustiça cultural ou simbólica, que envolve desde a dominação cultural por determinados padrões, passando pelo ocultamento e pela invisibilidade, até o desrespeito, a difamação e a desqualificação, é necessário o reconhecimento, isto é, alguma espécie de mudança cultural ou simbólica. Afinal, “[...] pessoas sujeitas à injustiça cultural e à injustiça econômica necessitam de reconhecimento e redistribuição. Necessitam de ambos para reivindicar e negar sua especificidade" (FRASER, 2006, p. 233), pois, se a abordagem focar somente para uma das injustiças, corre-se o risco de acabar criando ou ressaltando a outra. Soma-se à redistribuição e ao reconhecimento a paridade participativa, que deve estar presente em toda vida em sociedade, variando conforme o contexto de interação. "Relativamente a cada caso, devemos perguntar quem são os actores sociais entre os quais se exige que exista paridade de participação" (FRASER, 2002, p. 19).

A partir disso, entende-se que, para que a justiça social realmente aconteça, a contribuição da escola se torna fundamental, pois é nela que crianças e adolescentes passam grande parte do seu tempo, por vários anos seguidos, em busca de formação científica, preparação para o trabalho e construção de cidadania. Sendo assim, a justiça curricular deve se fazer presente, tornando-se uma das prioridades do trabalho escolar, pois, nesse mundo globalizado, o neoliberalismo permeia grande parte das relações sociais, políticas, culturais e econômicas, podendo influenciar as políticas educacionais e as concepções de currículo que fazem parte da escola. Sendo assim, entende-se que um currículo pode estar de acordo com as leis e os preceitos estabelecidos, mas, ao mesmo tempo, não contemplar a justiça curricular.

A justiça curricular, conforme Torres Santomé (2013, p. 9),

[...] é o resultado da análise do currículo que é elaborado, colocado em ação, avaliado e investigado levando em consideração o grau em que tudo aquilo que é decidido e feito em sala de aula respeita e atende às necessidades e urgências de todos os grupos sociais; lhes ajuda a ver, analisar, compreender e julgar a si próprios como pessoas éticas, solidárias, colaborativas e co-responsáveis [sic] por um projeto de intervenção sociopolítica mais amplo destinado a construir um mundo mais humano, justo e democrático. 
Cabe destacar que, para se alcançar a justiça curricular, entre outras coisas, é necessário assumir um projeto educacional de transformação, comprometido politicamente com a formação do cidadão crítico em relação à sociedade e ao seu entorno, não apenas contemplando aprendizagens e informações necessárias para o conhecimento científico. Nessa perspectiva, concordamos com o conceito de currículo na escola contemporânea, que segundo Ball (2010, p. 21), é o "[...] conjunto de experiências que molda seres humanos para transformá-los em pessoas".

$\mathrm{Na}$ contemporaneidade, vislumbra-se que a BNCC emerge como uma proposta de justiça social e curricular que visa assegurar "os direitos de aprendizagem e desenvolvimento" (BRASIL, 2018, p. 7). Entretanto, a concepção de garantia dos direitos de aprendizagem está vinculada a um projeto educacional neoliberal, em que o enfoque central está em melhorar os resultados nas avaliações externas. Conforme o documento da BNCC, a proposta de currículo nacional visa contribuir para a melhoria da educação, tendo em vista a expectativa de elevar o desempenho dos estudantes nas avaliações externas nacionais e internacionais.

A BNCC parece direcionar os conhecimentos a serem desenvolvidos nos processos educacionais e, principalmente, no alinhamento com as avaliações nacionais externas. Assim, reforça o controle e a centralidade do currículo a partir dos resultados atingidos nos exames. Essa política possui aparente caráter descentralizador, quando se apresenta como uma orientação curricular e de gestão. Sugere que o professor possui a autonomia de constituir uma prática de acordo com a realidade dos alunos, mas esta autonomia pode ser compreendida como uma autonomia imaginada. O processo de organização de conteúdos e das ações e práticas docentes passa a ser reestruturado a partir da lógica dos parâmetros e das diretrizes educacionais.

Percebe-se que a garantia dos direitos de aprendizagem está vinculada ao êxito nos testes. De tal modo, parece ser essa a concepção de justiça social e curricular presente na BNCC e que vai direcionar os conhecimentos a serem desenvolvidos nos processos educativos pelo alinhamento com as avaliações em larga escala.

Com relação à BNCC, esta também apresenta ilusória participação ao convidar a sociedade para a constituição do documento ${ }^{4}$. A participação defendida na discussão da elaboração do documento se distancia das proposições de Nancy Fraser (2002), pois a concepção apresentada pela proposta implica delegar as responsabilidades pelo cumprimento das futuras orientações, que passaram a ser evidentes em melhores resultados nas avaliações. Por exemplo, na seção de apresentação do documento é defendido que a base é extremamente importante e que "[...] deve ser acompanhado pela sociedade para que, em regime de colaboração, faça o país 
avançar [...], a BNCC passa agora às redes de ensino, às escolas e aos educadores. [...] [para que], em regime de colaboração, as mudanças esperadas alcancem cada sala de aula das escolas brasileiras" (BRASIL, 2018, p. 5), em virtude de que o governo federal, por meio do Ministério da Educação, está fazendo a sua parte, ao construir uma base curricular, ao mesmo tempo que denota a responsabilização das instituições e dos professores para que a base se efetive no contexto escolar e possa garantir os direitos de aprendizagem de todos.

A partir da homologação da BNCC, conforme o documento, as instituições de ensino de todo o país deverão realizar a construção dos currículos "[...] com base nas aprendizagens essenciais estabelecidas na BNCC, passando, assim, do plano normativo propositivo para o plano da ação e da gestão curricular que envolve todo o conjunto de decisões e ações definidoras do currículo e de sua dinâmica" (BRASIL, 2018, p. 20). Então, o papel da BNCC é de orientar a produção dos currículos nos sistemas educacionais e os professores, gestores e as famílias a colocar em ação esse currículo em acordo com um conjunto de atividades.

Essa política educacional pode ser compreendida como descentralização das práticas educacionais e curriculares para as autônomas. Essas preveem um Estado mínimo por meio de outro modo de regulação social, ao estimular um novo modo de gestão pública que devolve a autonomia institucional atrelada a um conjunto de parcerias em rede com o setor público, privado e cooperativo. Com isso, enfatiza a responsabilização e a participação pessoal e coletiva da sociedade civil, nas bases do discurso empreendedor, eficiente, competitivo, para atingir os melhores resultados e elevar a qualidade educacional.

Dessa forma, esse modelo educacional neoliberal faz com que se perca "[...] no processo a construção histórica da educação como um bem público, um direito social e que, como tal, não pode ser regulada como mercadoria, produto ou resultado passível de mensuração entregue a especialistas em medição e números" (OLIVEIRA, 2015, p. 641). Assim, em função da meritocracia e da busca de resultados, a educação como bem público e direito social de todos vai sendo ignorada e entregue à regulação do mercado.

A BNCC se alinha à lógica neoliberal quando visa obter bons resultados e melhores desempenhos sem necessariamente estar relacionada ao acúmulo de saberes, pois, "[...] ao homologar a Base Nacional Comum Curricular (BNCC) para a Educação Infantil e o Ensino Fundamental, o Brasil inicia uma nova era na educação brasileira e se alinha aos melhores e mais qualificados sistemas educacionais do mundo" (BRASIL, 2017, p. 5). Nesse sentido, entende-se que a BNCC possa 
estar reduzida a uma cultura de performatividade, visto que "[...] as convicções e os valores já não são importantes, é o resultado que conta” (BALL, 2005, p. 21). Assim, a qualidade da educação está pautada pelo desempenho e rendimento escolar como questão de performatividade, o que permite a competição entre os estudantes, os professores, as escolas e, em esfera internacional, entre os países, em busca das melhores posições nos rankings.

Para a lógica neoliberal, é a economia que rege e controla as ações e os planos de qualquer assunto de governo, bem como as decisões dos indivíduos. Com isso, o cidadão torna-se um mero consumidor do ensino, e começam a desaparecer as preocupações com o outro e com o trabalho coletivo. Nessa perspectiva, o ser humano torna-se uma mercadoria ou um meio para o mercado alcançar seus próprios objetivos (TORRES SANTOMÉ, 2013).

Constrói-se uma concepção de homem que tem como característica o "homo economicus racional”. Segundo Frigotto (2010, p. 70),

[...] o homo economicus é, pois, o produto do sistema social capitalista. Para a economia burguesa não interessa o homem enquanto homem, mas enquanto um conjunto de faculdades a serem trabalhas para que o sistema econômico possa funcionar como um mecanismo.

Esse modelo de sociedade cria um modelo de escola em que se tem como preceito que tudo é igual para todos, tornando-se vencedores aqueles que mais se dedicam e se esforçam para tal. "Assume-se a ideia de que a escola é igual para todos e de que, portanto, cada um chega onde suas capacidades e seu trabalho pessoal lhes permite", o que sustenta o discurso de um entendimento de justiça social baseada em uma educação meritocrática (GOMEZ, 2007, p. 16). Frigotto (2010, p. 80) expõe que se na sociedade o homem é livre para produzir e crescer de acordo com seu mérito, ou seja, dependendo "[...] única e exclusivamente do esforço, da capacidade, da iniciativa, da administração racional dos seus recursos, no mundo escolar a não aprendizagem, a evasão, a repetência são problemas individuais”.

Se todos os indivíduos são livres, se todos no mercado de trocas podem vender e comprar o que querem, o problema da desigualdade é culpa do indivíduo. Ou seja, se existem aqueles que têm capital é porque se esforçaram mais, trabalharam mais, sacrificaram o lazer e pouparam para investir. Dentro desta ótica, a sociedade capitalista não está dividida em classes, mas sim em estratos. A estratificação decorre de uma analogia do mecanismo de concorrência perfeita. Os indivíduos ganham seu lugar na hierarquia de estratificação segundo o critério do mérito (FRIGOTTO, 2010, p. 73).

Assim, em nenhum momento as desigualdades e tudo que ela pode acarretar são considerados para analisar o sucesso e/ou o fracasso, bem como o mérito dos 
indivíduos. Desse modo, o mérito contribui para a desresponsabilização do Estado em relação às desigualdades, como também da escola e do trabalho dos professores, que, muitas vezes, justificam o fracasso e a evasão escolar como desinteresse, falta de comprometimento e responsabilidade somente do próprio aluno. Com isso, são desconsiderados outros fatores importantes, como os contextos familiar, cultural, econômico e social em que se encontram os alunos, além de desresponsabilizar o Estado e os docentes do seu compromisso social (TORRES SANTOMÉ, 2003).

Nesse contexto, a escola passa a seguir os mesmos moldes da lógica empresarial de eficácia, que se pretende neutra nos discursos, mas está norteada por questões políticas e culturais. Para tal, apropria-se de palavras como performance, competência e aprendizado ao longo da vida, entrelaçando a lógica econômica com a escolar em prol da utilidade do saber, priorizando basicamente a preparação da formação profissional. Assim, o aluno torna-se responsável pela busca da aprendizagem e das suas escolhas e os professores passam a ser os mediadores do percurso formativo de cada estudante. "O mercado se torna assim, no lugar do Estado a instância mediadora vista como responsável por fixar os valores profissionais dos indivíduos" (LAVAL, 2004, p. 57).

Segundo o documento da BNCC, a proposta de unificar as aprendizagens deve possibilitar "[...] a superação da fragmentação radicalmente disciplinar do conhecimento, o estímulo à sua aplicação na vida real, a importância do contexto para dar sentido ao que se aprende e o protagonismo do estudante em sua aprendizagem e na construção de seu projeto de vida" (BRASIL, 2018, p. 15). A BNCC parece sustentar uma proposta que pretende incentivar o pensar, o aprender e o conhecer, ao valorizar a autonomia dos estudantes para escolhas e decisões futuras, inclusive com relação à continuidade do processo formativo, à inserção no mercado de trabalho e à construção dos seus projetos de vida.

A construção da proposta de um currículo unificado está justamente em implementar um padrão previsível de aplicabilidade de comportamentos desse sujeito aprendente, aquele que tem iniciativa, que é autogestor de sua vida e capaz de projetar um futuro de sucesso. Alinha-se com a ideia do empreendedor que planeja, projeta possibilidades existenciais e possui mais chances de sucesso na vida. A aprendizagem, então, é um empreendimento. $\mathrm{O}$ investimento individual que precisa ser realizado não é em conhecer, mas em aprender para buscar os diversos processos de formação, como obter um diploma e o permanente aperfeiçoamento profissional. 
A discussão desenvolvida não questiona a importância da educação escolar para a produtividade e o crescimento econômico do país, porém não se deve fazer desse o único objetivo da escola e de sua função social. Acredita-se em um projeto educacional que procure contribuir para o melhor desenvolvimento do cidadão e da sua vida em sociedade.

\section{Considerações finais}

Reitera-se que este estudo teve o intuito de analisar, a partir da BNCC, os atravessamentos do discurso neoliberal na escola em prol da justiça social. Nossa inquietação está em compreender como esse processo de padronização e uniformização, típico de uma proposta de base curricular nacional, reforça a constituição de uma agenda educacional neoliberal para as reformas educativas no contexto brasileiro.

A BNCC sustenta-se no discurso da democratização dos processos de ensino e aprendizagem, por isso a defesa de um currículo nacional como modo necessário de garantir os direitos de aprendizagem dos estudantes brasileiros. Percebeu-se que os discursos dessa proposta se aliam aos apelos argumentativos presentes nos discursos relacionados com um acordo globalizado de um projeto de sociedade. Durante a análise dos documentos oficiais, foram elencados vários excertos que exemplificam que a proposta da base vem comtemplar e instituir uma dimensão de currículo neoliberal.

Sendo assim, para que a escola possa contribuir com a justiça social, não se pode submetê-la a um projeto neoliberal de negociações políticas e financeiras que beneficiam somente o capital e a iniciativa privada, pois a escola não é uma empresa e seus objetivos não podem ser os mesmos. Defende-se a garantia da educação crítica e de qualidade e que proporcione a construção plena da cidadania.

Percebe-se que há um longo caminho a percorrer. Caminho de luta por uma educação que real e verdadeiramente contribua com a justiça social, proporcionando a todos os estudantes do país a oportunidade de se construir como um ser humano livre não só de direito, mas também de fato. Liberdade essa que vai muito além de um regime político, mas que se fundamenta na oportunidade de aprender na escola a discernir criticamente fatos e acontecimentos que envolvem não somente a vida do indivíduo isoladamente, mas a vida da sociedade em geral.

Desse modo, 
[...] o desafio que se impõe ás escolas públicas e a outras instituições de educação é o de promover um contexto para o desenvolvimento de outros meios de tornar-se alguém - modos mais fortalecedores do indivíduo e da coletividade, e mais condizentes com uma concepção democrática de eu e de comunidade (APPLE; CARLSON, 2003, p. 35).

Para tal, consideramos que conhecer, debater e discutir as políticas educacionais sob o enfoque da justiça social, em sua potencialidade conceitual, são fundamentais para se pensar e articular resistências contra esses discursos reformadores neoliberais, que têm não só regulado, mas também controlado o cenário educacional contemporâneo. Acredita-se que para a escola se tornar um espaço de justiça social é necessário que se tenha consciência da importância da justiça curricular, pois por meio dela poderemos ter clareza da necessidade de se lutar por um projeto de educação antagônico ao vigente, que é, por vezes, tão injusto e desigual.

Afinal, se não formos capazes de construir outras perspectivas mais democráticas, participativas e humanas para o futuro educacional dos estudantes, outras forças menos democráticas continuarão a fazê-lo, como é a imposição de um currículo nacional. Desse modo, continuaremos vivendo em uma sociedade em que o mérito é o discurso utilizado pela classe dominante para, disfarçadamente, justificar não somente o descaso pelas minorias, mas também as desigualdades sociais.

\section{Notas}

1 O presente estudo contou com financiamento da Coordenação de Aperfeiçoamento de Pessoal de Nível Superior e do Conselho Nacional de Desenvolvimento Científico e Tecnológico.

2 O Brasil não faz parte da OCDE, mas desenvolve processos de cooperação desde 1990 e participa das avaliações na área da educação, como o Pisa, que é de responsabilidade do Instituto Nacional de Estudos e Pesquisas Educacionais Anísio Teixeira (HYPOLITO, 2010).

3 Para maiores informações, acessar: http://movimentopelabase.org.br/quem-somos/.

4 Para aprofundar a discussão sobre esse procedimento denominado pelo Ministério da Educação como democrático, em que afirma ter privilegiado o debate, as negociações e as contribuições entre os diversos atores da sociedade envolvidos no processo de produção e elaboração dessa política curricular, sugere-se a leitura do texto de Avelar e Ball (2017).

\section{Referências}

AVELAR, Marina; BALL, Stephen. Mapping new philanthropy and the heterarchical state: the mobilization for the national learning standards in Brazil. International Journal of Educational Development, Elsevier, v. 64, p. 65-73, 2017.

APPLE, Michael W.; CARLSON, Dennis. Teoria educacional crítica em tempos incertos. In: HYPOLITO, Álvaro Moreira; GANDIN, Luís Armando. Educação em tempos de incertezas. 2. ed. Belo Horizonte: Autêntica, 2003. p. 11-58. 
BALL, Stephen. Diretrizes políticas globais e relações políticas locais em educação. Currículo sem Fronteira, Rio de Janeiro, v. 1, n. 2, p. 99-116, jul./dez. 2001.

BALL, Stephen J. Intelectuais ou técnicos? O papel indispensável da teoria nos estudos educacionais. In: BALL, Stephen J.; MAINARDES, Jefferson. Políticas educacionais - questões e dilemas. São Paulo: Cortez, 2011.

BALL, Stephen. Performatividade, privatização e o pós Estado. Educação e Sociedade, Campinas, v. 25, n. 89, p. 1105-1126, set./dez. 2004.

BALL, Stephen J. Profissionalismo, gerencialismo e performatividade. Cadernos de Pesquisa, São Paulo, v. 35, n. 126, p. 539-564, set./dez. 2005.

BALL, Stephen. Vozes/redes políticas e um currículo neoliberal global. Espaço do Currículo, João Pessoa, PB, v. 3, n. 1, p. 485-498, mar./set. 2010.

BASE NACIONAL COMUM. Movimento pela Base Nacional Comum. 2013. Disponível em: http://movimentopelabase.org.br/. Acesso em: 03 mar. 2019.

BRASIL. Base Nacional Comum Curricular - BNCC. Brasília, DF: Ministério da Educação, 2017. Disponível em: http://basenacionalcomum.mec.gov.br/wp-content/uploads/2018/02/bncc-20dez-site.pdf/. Acesso em: 22 jan. 2019.

BRASIL. Ministério da Educação. Base Nacional Comum Curricular - Educação é a Base. Brasília, 2018. Disponível em: http://basenacionalcomum.mec.gov.br/wp-content/uploads/2018/12/ BNCC_19dez2018_site.pdf. Acesso em: 22 jan. 2019.

CARVALHO, Luís M. Intensificação e sofisticação dos processos da regulação transnacional em educação: o caso do programa internacional de avaliação de estudantes. Educação e Sociedade, Campinas, v. 37, n. 136, p. 601-607, jul./set. 2016.

CHARLOT, Bernard. A mistificação pedagógica: realidades sociais e processos ideológicos na teoria da educação. Trad. Maria José do Amaral Ferreira. ed. rev. e ampl. São Paulo: Cortez, 2013.

CONNEL, Raewyn. Pobreza e Educação. In: GENTILI, Pablo (org.). Pedagogia da exclusão: crítica ao neoliberalismo em educação. 19. ed. Petrópolis, RJ: Vozes, 2013.

DELORS, Jacques. Educação: um tesouro a descobrir. Relatório para a UNESCO da Comissão Internacional sobre Educação para o século XXI. São Paulo: Cortez, 1996.

FRASER, Nancy. A justiça social na globalização: redistribuição, reconhecimento e participação. Revista Crítica de Ciências Sociais, Coimbra, v. 63, p. 7-20, out. 2002.

FRASER, Nancy. Da redistribuição ao reconhecimento? Dilemas da justiça numa era "pós-socialista”. Cadernos de Campo, São Paulo, n. 14/15, p. 231-239, 2006.

FRASER, Nancy. Escalas de justicia. Trad. Antoni Martinez Riu. Barcelona: Herder Editorial, S.L, 2012.

FRIGOTTO, Gaudênio. A produtividade da escola improdutiva: um (re)exame das relações entre educação e estrutura econômico-social capitalista. 9. ed. São Paulo: Cortez, 2010.

GARCIA, Maria Manuela Alves. Políticas educacionais contemporâneas: tecnologias, imaginários e regimes éticos. Revista Brasileira de Educação, Rio de Janeiro, v. 15, n. 45, set./dez. 2010. 
GOMEZ, A. I. Pérez. As funções sociais da escola: da reprodução à reconstrução crítica do conhecimento e da experiência. In: SACRISTÁN, J. Gimeno. Compreender e transformar o ensino. 4. ed. Porto Alegre: Artmed, 2007. p. 13-25.

HYPOLITO, Álvaro. Políticas curriculares, Estado e regulação. Educação e Sociedade, Campinas, v. 31, n. 113, p. 1337-1354, out./dez. 2010.

LAVAL, Christian. A escola não é uma empresa. O neoliberalismo em ataque ao ensino público. Trad. Maria Luiza M. de Carvalho e Silva. Londrina: Planta, 2004.

LINGARD, Bob. Pisa: fundamentações para participar e acolhimento político. Educação e Sociedade, Campinas, v. 37, n. 136, p. 601-607, jul./set. 2016.

MACEDO, Elizabeth. Base Nacional Curricular Comum: novas formas de sociabilidade produzindo sentidos para educação. Revista e-Curriculum, São Paulo, v. 12, n. 3, p. 1530-1550, out./ dez. 2014.

NEWMAN, Janet; CLARKE, John. Gerencialismo. Educação \& Realidade, Porto Alegre, v. 37, n. 2, p. 353-381, maio/ago. 2012.

OLIVEIRA, Dalila A. Nova gestão pública e governos democrático-populares: contradições entre a busca da eficiência e a ampliação do direito a educação. Educação e Sociedade, Campinas, v. 36 , n. 132 , p. $625-646$, jul./set. 2015.

POPKEWITZ, Thomas S. A reforma como administração social da criança: a globalização do conhecimento e do poder. In: BURBULES, Nicholas; TORRES, Carlos Alberto (org.). Globalização e educação: perspectivas críticas. Porto Alegre: Artmed, 2004.

TORRES SANTOMÉ, Jurjo. A educação em tempos de neoliberalismo. Porto Alegre: Artmed, 2003.

TORRES SANTOMÉ, Jurjo. Currículo escolar e justiça social: o Cavalo de Tróia da educação. Porto Alegre: Penso, 2013. 